\title{
Numerical modelling of thermal evolution in hot metal coiling
}

\author{
N. Troyani", L.E. Montano** y O.M. Ayala***
}

\begin{abstract}
The use of coiling and uncoiling in the transfer table stage has important effects on the downstream temperature evolution throughout the hot bar in hot rolling, consequently, it has significant effects on both the uniformity of final mechanical properties and uniformity of final metallurgical properties. Consideration is given herein to the evolution of bar distribution of temperature in the transfer table, when coiling is present, in order to establish possible causes for the lack of the stated uniformity for eventual possible solutions. To address these issues, the mathematical equation of heat diffusion in a shape changing domain, is solved using a novel numerical strategy that uses both Finite Elements and Finite Differences. Numerical results are presented.
\end{abstract}

Keywords Temperature evolution. Metal coiling. Finite elements. Finite differences.

\section{Modelado numérico de la evolución térmica en el bobinado de metales en caliente}

\begin{abstract}
Resumen El uso de estrategias para el bobinado y enderezado en la etapa de la mesa de transporte tiene repercusiones importantes en la evolución de la temperatura, aguas abajo, en el planchón de metal caliente; en consecuencia, tiene efectos significativos sobre la uniformidad de las propiedades mecánicas y metalúrgicas finales una vez concluido el proceso. Este trabajo estudia la evolución de la distribución de temperatura en la etapa de la mesa de transporte, en procesos de bobinado, con el fin de establecer causas que puedan originar la ausencia de la citada uniformidad. Para el estudio se resuelve la ecuación de difusión del calor en un dominio que cambia con el tiempo en una novedosa estrategia numérica que integra Elementos Finitos y Diferencias Finitas. Se presentan resultados numéricos de la simulación.
\end{abstract}

Palabras clave Evolución de temperatura. Bobinado de metales. Elementos finitos. Diferencias finitas.

\section{INTRODUCTION}

Coiling, (Fig. 1) is used in the transfer table stage of hot metal mills, and it is also used in the run out table after the finishing stands as well. Using coiling devices in the transfer table results in significant temperature loss reduction and, when done properly, can result also in a more uniform temperature at the entry of the finishing stands, producing both more uniform final mechanical properties and more uniform metallurgical properties as well. One of the problems facing the industry is the lack of sufficient uniformity in the properties of the final product owing to, basically, non uniform temperature evolution in the hot bar during the entire rolling process. The Coilbox ${ }^{[1]}$, a Steltech patent, is just an example of a specific coiling device.

The aim in this work is to develop a mathematical and numerical framework to determine an estimate of hot strip temperature evolution in the transfer table that results in bar uneven temperature distribution at the entry of the finishing stands, based on a given initial temperature at the exit of the roughing stand, (Fig. 2) when coiling is present.

In figure 1, the FE discretization in the coiling plane, FD points in the widthwise direction of the bar and the coordinate directions as well are shown. Due to symmetry just half of the width of

$\left(^{*}\right) \quad$ Centro de Métodos Numéricos en Ingeniería, Universidad de Oriente, Apdo. 4327, Puerto La Cruz, Venezuela, E-mail: ntroyani@cantv.net

${ }^{* *}$ Rolling Technology Consultant, Pittsburgh, Pa, USA.

$\left(^{* * *}\right)$ Department of Mechanical Engineering, University of Delaware, USA. 


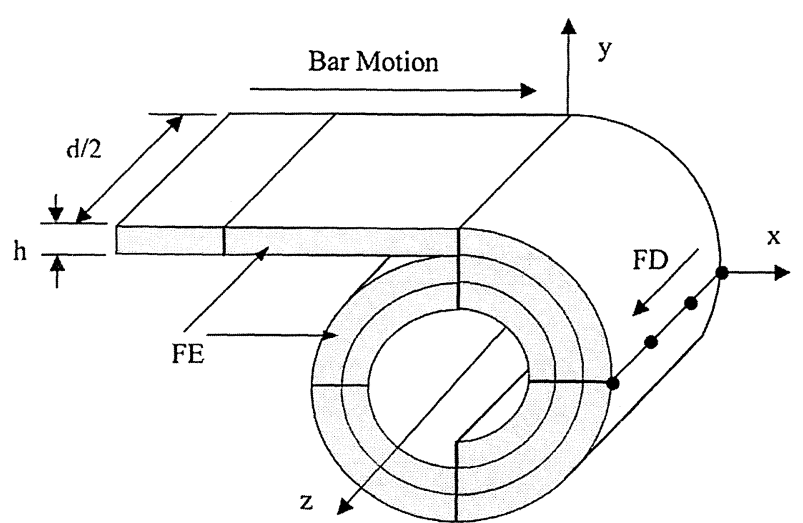

Figure 1. Schematic of bar coiling initiation showing FE and FD discretization.

Figura 1. Esquema del comienzo del bobinado indicando la discretización en EF y DF.

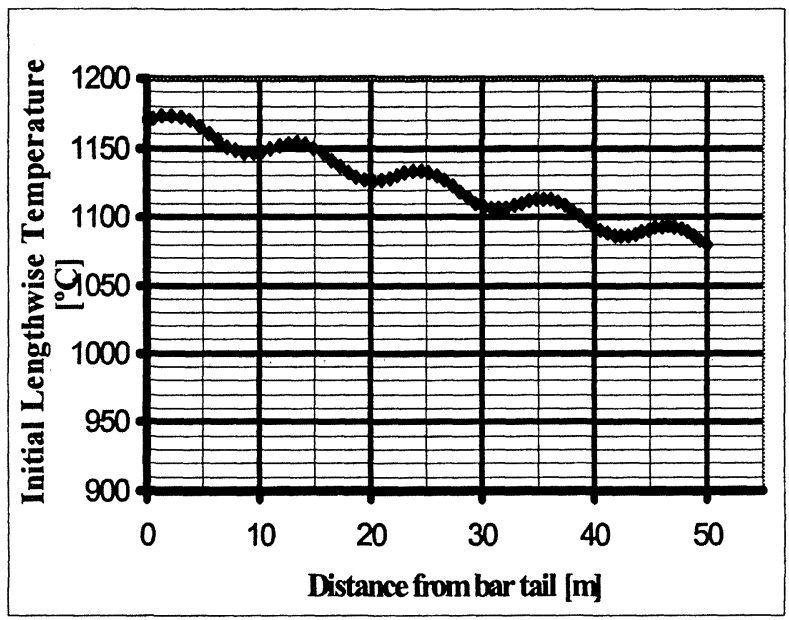

Figure 2. Initial lengthwise distribution of temperature.

Figura 2. Distribución longitudinal de la femperatura inicial.

the bar is retained in the calculations. An account of a 2-D model, its numerical solution and a particular application for the coiling problem can be found in the bibliography ${ }^{[2-4]}$, where the solution was achieved using geometrically adaptive finite elements, 8-node isoparametric elements ${ }^{[5]}$ to accommodate the shape changing of the bar.

Even though the employed model and procedure was applied to coiling processes that take place in the transfer table, it should be pointed out that with minor changes, these procedures would be applicable to determine temperature evolution for coiling at the run out table ${ }^{[6 \text { and } 7]}$, as well. Recent studies regarding applications where hot metal mill processing with coiling takes place in connection with analyses dealing with mechanical and micro structural properties, can be found in reference $^{[8-12]}$. From a mechanical prospective, an interesting recent application using FE in hot rolling is given in the bibliography ${ }^{[13]}$. These types of studies could provide an estimate of the variation of temperature to be added to the analysis presented herein due to heat generated from plastic deformation both during the rolling process and coiling processes.

\section{THE MATHEMATICAL MODEL AND NUMERICAL SOLUTION}

The equation governing the temperature evolution in the bar is the parabolic partial differential equation (PDE) of heat diffusion ${ }^{[14]}$ given by:

$$
\nabla \cdot[k \nabla T]=c \rho \frac{\partial T}{\partial t} \forall(x, y, z) \in \Omega_{x y z}(t)
$$

where, $k, T, c, \rho, t$ represent thermal conductivity, temperature, heat capacity, density and time.

$\Omega_{x y z}(t)=\left\{(x, y, z, t) \mid 0<x<L, 0<y<h,-d / 2<z<d / 2,0<t \leq t^{*}\right\}$

represents the time dependent domain. $L, h, d, t^{*}$ represent bar length, bar thickness, bar width and an arbitrary final time respectively. The three dimensional vectorial differential operator has the usual form

$$
\nabla=\frac{\partial}{\partial x_{i}} \rho_{i}+\frac{\partial}{\partial y_{i}} \rho_{j}+\frac{\partial}{\partial z_{k}} \rho_{k}
$$

where $\rho_{\mathrm{i}}, \rho_{\mathrm{j}}$ and $\rho_{\mathrm{k}}$ represent the usual unit vectors in the coordinate directions.

The boundary conditions (BC) are the combined convective and radiative boundary conditions for the edges and ends of the bar $(x=0$, $\mathrm{x}=\mathrm{L}$ ) is given by

$$
-k \frac{\partial T}{\partial h}=h_{c r}\left(T-T_{\infty}\right) \forall(x, y, z) \in \partial \Omega_{x y z}(t)
$$

where $h_{c r}=h_{c}+h_{r}$. The indicated derivative represents the outward normal derivative. $h_{c}, h_{r}, T_{\infty}$ and $\partial \Omega_{x y z}(t)$ represent convective heat transfer film coefficient, equivalent radiative heat transfer film coefficient, temperature at a sufficient distance from the boundary of the bar and time dependent boundary of the bar respectively. With an initial uniform temperature, an initial condition is assumed in the form: 


$$
T(x, y, z, 0)=T^{*} \forall(x, y, z) \in \Omega_{x y z}(0)
$$

The reader will find a description of the bar motion based on the coordinate system of figure 1 in reference ${ }^{[3]}$. It is assumed that surfaces facing one another from adjacent wraps exchange heat according to a boundary condition of the form ${ }^{[3-4]}$

$$
-k \frac{\partial T}{\partial h}=h_{t c c f}\left(T-T_{\infty}\right) \forall(x, y, z) \in \partial \Omega_{x y z}(t)
$$

where $h_{\text {tccf }}$ is defined as the thermal contact conductance consistent film coefficient, $T$ is the heat emitting surface temperature, and $T_{\infty}$ is the heat receiving surface temperature.

The problem posed in equations (1) through (4) is solved by a numerical strategy which at each time step integrates via the Numerical Superposition Principle a 2-D FE solution ( $\left.\mathrm{T}_{\mathrm{FE}}^{\mathrm{xy}}\right)$ in the $x-y$ plane, the coiling plane, with a 1-D FD solution $\left(T_{F D}^{z}\right)$ in the $z$ direction, width direction, of the bar. From reference ${ }^{[2]}$, the summation form of the NSP is used here as follows:

$\left[T(x, y, z, t)-T^{*}\right]=\left[T_{F E}^{x y}(x, y, t)-T^{*}\right]+\left[T_{F D}^{z}(z, t)-T^{*}\right]$

The indicated FE solution in (5) corresponds to the following 2-D equation:

$$
\nabla \cdot[k \nabla T]=c \rho \frac{\partial T}{\partial t} \forall(x, y) \in \Omega_{x y}(t)
$$

where $\Omega$ xy $(\mathrm{t})=\{(x, y, t) \mid 0<x<L, 0<y h, 0<t$ $\left.\leq t^{*}\right\}$ and subjected to boundary conditions of the type indicated in equations [2 and 4] once wrap contact takes place as well as an initial condition of the type indicated in equation [3]. The differential operator is the 2-D equivalent of the one given above. This non-steady state equation is solved using an 8-node isoparametric element variable time step Crank-Nicolson approach. The indicated FD solution in equation 5 corresponds to the following $1-D$ equation:

$$
k \frac{\partial^{2} T}{\partial z^{2}}=c \rho \frac{\partial T}{\partial t} \forall z \in \Omega_{z}(t)
$$

where $\Omega_{z}(t)=\left\{(z, t) \mid 0<z<d / 2,0<t \leq t^{*}\right\}$, subjected to a symmetry condition of the type:

$$
\frac{\partial T}{\partial t}=0 \text { at } z=0
$$

an initial condition

$$
T(z, 0)=T^{*}
$$

and a combined convective-radiative boundary condition at the edge of the type:

$$
-k \frac{\partial T}{\partial t}=h_{c r}\left(T-T_{\infty}\right) \text { for } z=d / 2
$$

The FD solution used here for equation (7) is based on the standard three point finite difference approximation, given below:

$$
\frac{\partial^{2} \mathrm{~T}}{\partial z^{2}} \approx \frac{\mathrm{T}_{k-1}-2 \mathrm{~T}_{\mathrm{k}}+\mathrm{T}_{\mathrm{k}+1}}{(\Delta z)^{2}} \quad 1 \leq k \leq n_{z}, \Delta z=z_{k}-z_{k-1}
$$

$n_{z}$ represents the number of finite difference points in the $z$ direction, and $z_{k}$ represents the coordinate of a generic node in the $z$ direction. A uniform FD grid of nodes was used in the present work, $\Delta z=$ const.

It should be pointed out that the proposed numerical scheme should be regarded as an approximate one in the sense that even though the $\mathrm{PDE}$ is both linear (since the thermal properties are taken as an average instead of temperature dependent) and separable, the BC's are not linear, they are in fact linearized at each computational time step. Similarly, the BC's are separable only in an approximate sense as well. On the other hand the initial conditions are in fact entirely separable.

\section{RESULTS}

The numerical results at selected points in the transfer bar discussed below correspond to a $0.01 \mathrm{~m}$ thick, $1.0 \mathrm{~m}$ wide and $50.0 \mathrm{~m}$ long steel bar in a $30.0^{\circ} \mathrm{C}$ environment, with the following average steel thermal properties. Thermal conductivity $27.2 \mathrm{~W} / \mathrm{m}^{\circ} \mathrm{C}$, density $7,520.0 \mathrm{~kg} / \mathrm{m}$, heat capacity $670.0 \mathrm{~J} / \mathrm{kg}^{\circ} \mathrm{C}$ and an emissivity of 0.838 .

Actual mill pyrometer recorded measurements at the exit of the roughing stands indicate a longitudinally sinusoidal distribution of temperature (skid marks, representable with a sine curve), hence the initial distribution indicated in figure 2. Although not required in the method, temperature is assumed uniform in the $z$ direction.

Figures 3 and 4 exhibit the relatively complex evolution of temperature during coiling and uncoiling at six selected nodal points in three sets of two curves each for two specific longitudinal 


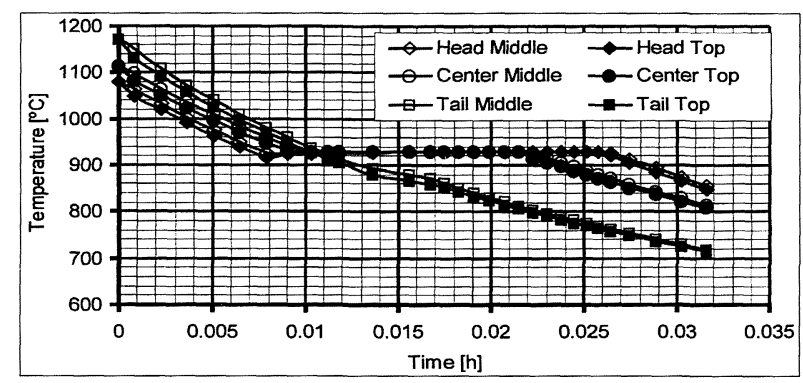

Figure 3. Bar evolution of temperature for six selected points on the plane $\mathrm{z}=0.0 \mathrm{~m}$.

Figura 3. Evolución de la temperatura del planchón para los seis puntos seleccionados sobre el plano $\mathrm{z}=0,0 \mathrm{~m}$.

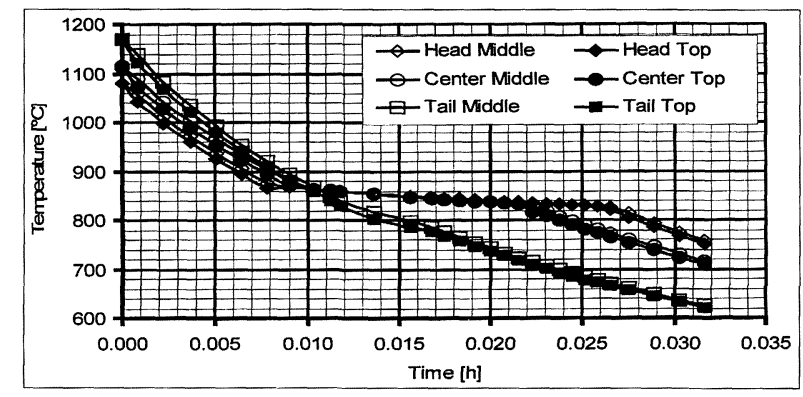

Figure 4. Bar evolution of temperature for six selected points on the plane $z=0.5 \mathrm{~m}$.

Figura 4. Evolución de la temperatura del planchón para los seis puntos seleccionados sobre el plano $z=0,5 \mathrm{~m}$.

planes, $z=0 \mathrm{~m}$ (center of the bar) and $z=0.5 \mathrm{~m}$ (longitudinal edge of the bar) respectively. These results correspond to zero radiation shielding.

\section{DISCUSSION AND CONCLUSIONS}

Figure 5, clearly shows the effect of the widthwise heat loss near the edge of the bar $(z=0.5)$. This heat loss increases noticeably the slopes of the temperature evolution curves. In fact, it can be observed that there is a difference of $100.0^{\circ} \mathrm{C}$, approximately, between the curves in figures 3 and 4 at the end of the coiling and uncoiling process for the temperatures at the six points considered. This difference increases with bar length since both total coiling times and total uncoiling times would be longer then.

Figures (3-5) indicate important sources of non uniform temperature that result from bar heat loss and coiling of the bar. These sources are, essentially, the initial distribution of temperature at the exit of the roughing stands, the loss of heat to the environment, the longitudinal edge

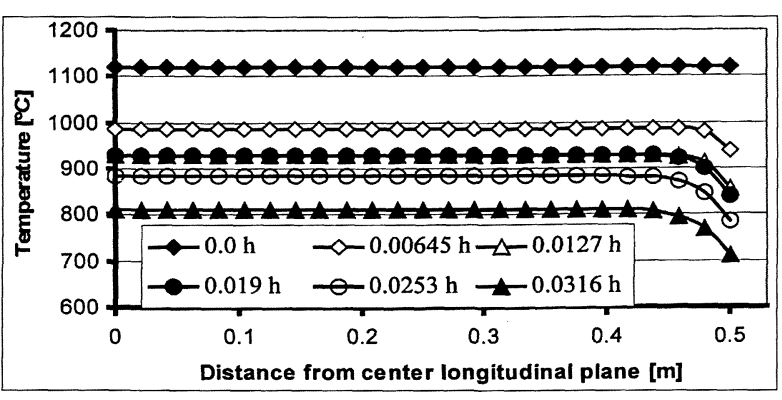

Figure 5. Widthwise evolution of bar temperatura at $x=$ $\mathrm{L} / 2$ at indicated times.

Figura 5. Evolución de la temperatura en la dirección del ancho del planchón (dirección $z$ ) para $x=L / 2$ para los tiempos indicados.

(widthwise) loss of heat and the loss of heat at the tail edge and head edge of the bar.

Coiling in the transfer table certainly reduces heat loss to the environment as is indicated by the middle parts of the curves in Figures (3-4). The model corroborates that the lengthwise edge radiation shielding does help reduce the widthwise non uniform distribution of temperature throughout the process, that is, the difference between the curves in figures 3 and 4 .

The head edge and tail edge temperature loss reduction represent an important challenge at this point since presently the bar ends need to be cropped, in non-continuous processes due to low temperature, resulting in lower productivity.

On the other hand, reducing the lengthwise temperature differences as the bar enters the finishing stands (near uniform temperature rolling) requires a full optimization study based on initial distribution of temperature, currently under way.

\section{Acknowledgements}

Work Partially supported by Consejo de Investigación, Universidad de Oriente, Venezuela.

\section{REFERENCES}

[1] W. SMITH, AISE Year Book (1981) 432-436.

[2] N. TroYani, Numerical Heat Transfer A 30 (1996) 849 . 858.

[3] N. Troyani, Proc. VII Congreso Latinoamericano de Transferencia de Calor y Materia, LATCYM'98, Vol. 3, Salta, Argentina, 1998, pp. 783-786.

[4] N. Troyani and L. Montano, J. Braz. Soc. Mech. Sci. XXI (1999) 655-663. 
[5] E.B. Becker, G.F. CAREY and J.T. Oden, Finite Elements: An Introduction, Chap. 4, Ed. Prentice Hall Engelwood Cliff, New jersey, USA, 1981.

[6] K. ImAzU, Trans. Jap. Soc. Mech. Eng. 63 C (1997) 2132 2137.

[7] K.M. Browne, J. Dryden and M. Assefpour, ASME, Mater. Division 70 (1995) 187-197.

[8] M. Militzer, E.B. Hawbolt and T.R. Meadowcroft, Metall. Mater. Trans. A-Phys. Metall. Mater. Sci. 31 (2000) 1247-1259.

[9] S.J. PARK, B.H. HonG, S.C. BAIK and K.H. OH, ISIJ Int. 38 (1998) 1262-1269.
[10] V. Samarasekera, C.A. Muojekwu, D.Q. Jin and J. K.Brimacombe, Proc. Mech. Work. Steel Process. Conf. (1997) 861-873.

[11] M.K. ICHIRO and O. NAOHIRO, Int. J. Mach. Tool Manuf. 39 (1999) 403-413.

[12] A. Artigas, M. Páez, Y. Houbaert, A. Monsalve and D. Celentano, Rev. Metal. Madrid 38 (2002) 339-347.

[13] M.A. Cavaliere, M.B. Goldschmit and E.N. Dvorkin, Int. J. Numerical Methods Eng. 52 (2001) 1411-1430.

[14] M.N. Ozisik, Heat Conduction, Chap. 2, $2^{\text {nd }}$ Edition, Ed. Wiley, New York, USA, 1993. 